\title{
PRASI (KOMIK TRADISIONAL BALI) DI ERA DIGITAL, TANTANGAN DAN PELUANG
}

\author{
Ida Bagus Rai \\ Jurusan Pendidikan Bahasa Bali, Fakultas Bahasa dan Seni \\ Universitas Pendidikan Ganesha \\ Jalan Jend. A. Yani 67 Singaraja 81116, Telp. 0362-21541, Fax. 0362-27561 \\ Email: bagus.rai@undiksha.ac.id
}

\begin{abstract}
Prasi (traditional Balinese comics) is one aspect of Balinese culture that supports the noble values and influences for the people of Bali. Prasi is a combination of two types of skills, namely the skills to write and draw on palm leaves. Prasi-shaped prose that accompanied the image using palm leaves as media. The types of stories written on prasi usually come from the epics of Ramayana and Bharatayudha. But there are also written from the story of Tantri. Prasi has function as entertainment media. The meaning contained in prasi is the values of religion and culture of Bali. The challenge of pration in the digital era, the community of the prasi is diminishing. The interest of the younger generation of Bali to write a few more prasi. Opportunities in the present era as a medium for preserving culture and religion in Bali. Prasi until now still favored by foreign tourists used as a cendramata.
\end{abstract}

Keywords; Prasi, digital era, challenge, opportunity.

\begin{abstract}
ABSTRAK
Prasi (komik tradisional Bali) merupakan salah satu aspek budaya Bali yang mendukung nilainilai luhur dan berpengaruh bagi masyarakat Bali. Proses pembuatan prasi membutuhkan perpaduan dua jenis keterampilan, yaitu keterampilan menulis dan menggambar pada daun lontar. Prasi berbentuk prosa yang disertai gambar menggunakan daun lontar sebagai media. Jenis cerita yang ditulis pada prasi biasanya berasal dari epos Ramayana dan Bharatayudha. Namun, ada juga yang ditulis dari cerita tantri. Prasi mempunyai fungsi sebagai media hiburan. Makna yang terkandung pada prasi adalah nilai-nilai agama dan budaya Bali. Tantangan prasi di era digital, komunitas prasi semakin berkurang. Minat generasi muda Bali untuk menulis prasi semakin sedikit. Peluang prasi di era sekarang sebagai media untuk melestarikan budaya dan agama di Bali. Prasi sampai saat ini masih disenangi oleh wisatawan asing digunakan sebagai cendramata.
\end{abstract}

Kata kunci; Prasi, era digital, tantangan, peluang.

\section{PENDAHULUAN}

Kesusastraan Bali merupakan kekayaan masyarakat Bali karena semuanya sangat berhubungan dengan seni dan budaya, serta keadaan sosial masyarakat Bali. Kesusastraan Bali adalah hasil daya cipta manusia (pengarang) berdasarkan ilham atau wahyu yang kemudian ditulis menggunakan bahasa yang baik ( Gautama, 2007:27). Kesusastraan
Bali kebanyakan bersifat imajinatif. Kesusastraan Bali tersebut dapat dibedakan menjadi dua, yaitu kesusastraan Bali Purwa dan kesusastraan Bali Anyar. Berdasarkan konvensinya prasi termasuk dalam karya sastra Bali Purwa.

Kesusastraan Bali tersebut dapat berupa gancaran, palawakia, dan tembang (Gautama, 2009:35). Gancaran adalah karya sastra berbentuk prosa. Karya sastra gancaran ini 
tidak menggunakan metrum seperti tembang pada kekawin. Jadi, cara membaca gancaran adalah biasa saja tanpa irama (pacapaliring). Prasi termasuk salah satu dari karya sastra tradisional berbentuk gancaran. Karena pada prasi cerita yang ditulis tidak menggunakan irama (tembang).

Selain bentuk-bentuk di atas, dalam lontar-lontar kuno juga terdapat gambar yang sering disebut rajah (Rai, 2011:7). Gambar tersebut ada yang berbentuk dewa-dewi, manusia, raksasa, binatang, pohon, dan lain sebagainya. Gambar atau rajahan tersebut biasanya mengandung unsur magis. Sedangkan huruf yang digunakan menulis kesusastraan Bali purwa itu adalah aksara Bali. Media yang digunakan dalam menulis berupa daun lontar.

Di tengah berkembangnya sebuah era digital seperti saat ini, yang segalanya serba canggih dan tanpa batas, banyaknya karyakarya sastra modern seperti kartun, film animasi membuat prasi seakan tidak punya ruang. Walaupun demikian, upaya pelestarian telah dilakukan oleh pemerintah Bali.

\section{PEMBAHASAN}

\section{Prasi (Komik Tradisional Bali)}

Prasi (komik tradisional Bali) berasal dari dua kata yaitu paras yang berarti wajah dan siwulan yaitu daun lontar. Dengan demikian, prasi merupakan wajah atau lukisan yang dibuat pada daun lontar yang kemudian berisi cerita-cerita sesuai lukisan.

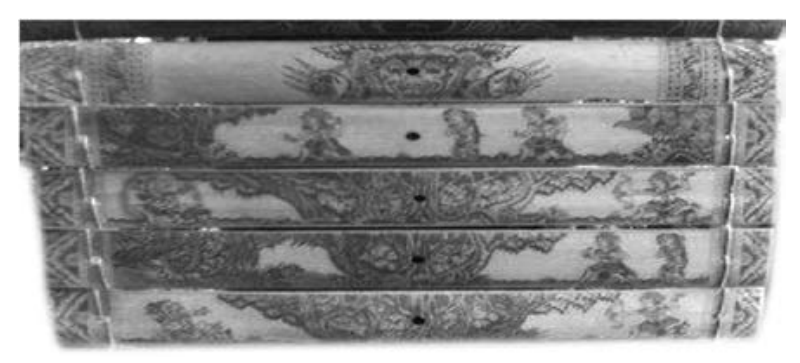

Gambar 1. Wujud lontar prasi

Selain itu, prasi ini terbentuk dari dua unsur keterampilan yaitu menggambar dan menulis. Perpaduan kedua keterampilan tersebut dirangkai pada media daun lontar. Bagian depan lontar, digambar sesuai dengan cerita. Di bagian lain, ditulis cerita yang mendeskripsikan gambar tersebut. Dengan demikian, prasi merupakan salah satu karya local wisdom. Prasi dibuat oleh masyarakat Bali dan mencerminkan kehidupan dan kepribadian masyarakat Bali, yang sarat dengan nilai-nilai luhur dan pembelajaran budi pekerti. Jadi, prasi adalah cerita bergambar masyarakat Bali yang ditulis pada daun lontar.

Komunitas pembuat prasi tersebar di seluruh kabupaten dan kotamadya di Bali. Mereka semua ahli dalam menulis prasi. Biasanya penulis prasi ini berasal dari kalangan generasi tua. Generasi muda yang menekuni menulis prasi bisa dibilang masih sedikit. Hal ini disebabkan generasi muda Bali masih menuntut ilmu atau bekerja pada suatu instansi, sehingga waktu yang masih tersisa untuk menulis prasi kurang tersedia. Selain itu, dalam menulis prasi, diperlukan keterampilan yang cukup seperti keterampilan menulis aksara Bali dan melukis tokoh pewayangan di daun lontar.

Melukis wayang di daun lontar tidak sama dengan melukis di kertas atau di kain kanvas. Alat yang digunakan pun berbeda. Melukis di daun lontar menggunakan pengrupak (pisau kecil yang ujungnya tajam). Konsentrasi ketika menggoreskan pengrupak sangat diperlukan sehingga tidak terjadi kesalahan karena goresan yang salah tidak dapat diperbaiki dengan bahan apapun. Setelah selesai menggambar, dituliskan cerita yang sesuai dengan gambar yang telah dibuat. Pewarna yang digunakan terbuat dari buah kemiri yang dibakar kemudian digiling halus.

Cerita yang sering diangkat dalam prasi ini adalah cerita Ramayana dan Baratayudha. Namun cerita lain seperti Tantri juga pernah dibuat sesuai dengan pesanan. Demikian juga dengan cerita-cerita yang lainnya.

Untuk melestarikan prasi ini, pemerintah daerah Bali telah melakukan upaya melalui pembinaan-pembinaan ke daerah-daerah, serta menyelenggarakan lomba pembuatan/ penulisan prasi ini pada kegiatan-kegiatan kejuaraan seperti lomba menulis prasi di Pekan 


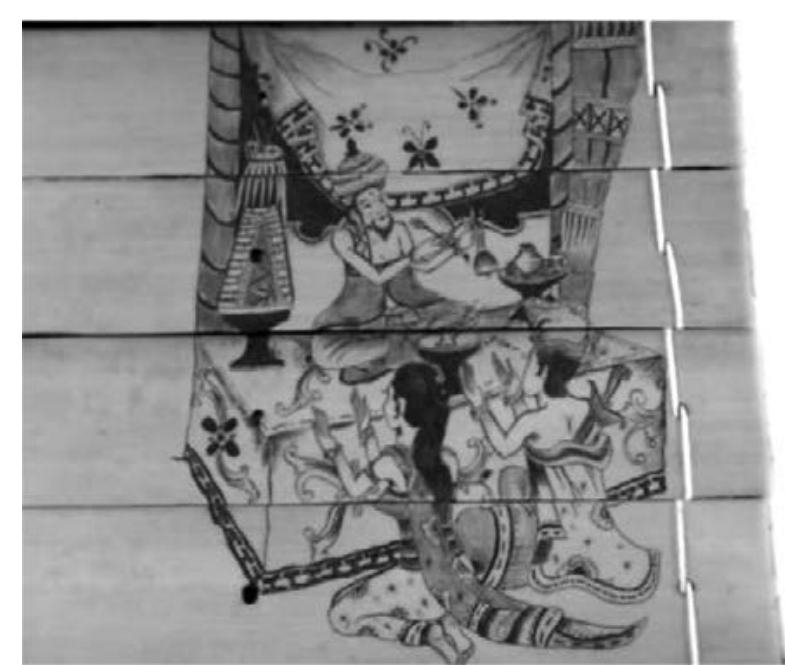

Gambar 2. Tampilan gambar pada lontar prasi

Kesenian Bali (PKB). Usaha ini telah dilaksanakan meskipun hasilnya belum maksimal karena belum menunjukkan peningkatan signifikan terhadap meningkatnya jumlah peserta dari kalangan muda. Peserta lomba nyurat prasi masih didominasi oleh generasi tua. Generasi muda belum bisa unjuk gigi.

\section{Bentuk Prasi}

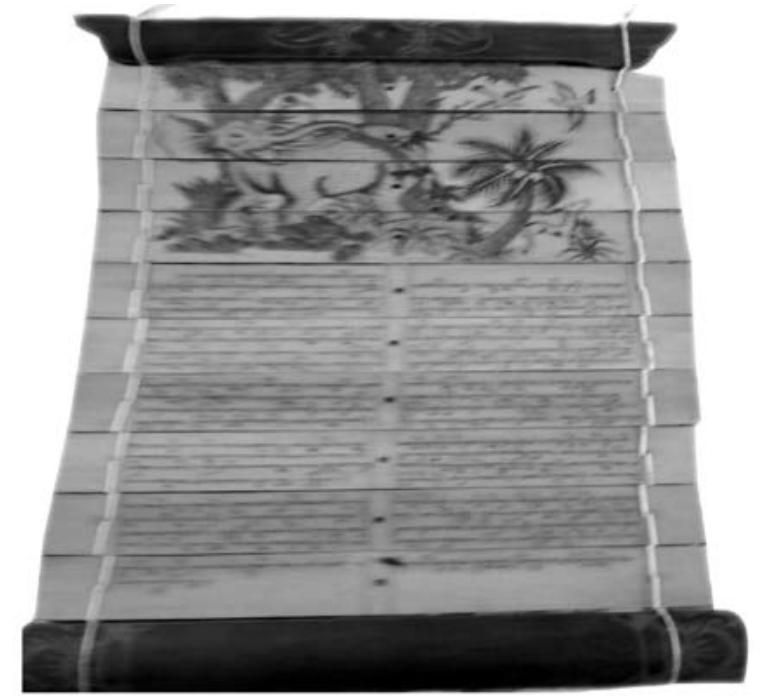

Gambar 3. Rangkaian cakepan prasi

Prasi berbentuk cerita bergambar tradisional Bali. Karena cerita bergambar jelas unsur pembentuknya yaitu cerita dan gambar. Prasi sebagai cerita tentu mengikuti unsurunsur instrinsik dan ekstrinsik karya sastra. Gambar pada prasi disesuaikan dengan alur cerita yang dibuat. Tokoh -tokoh dalam cerita dilukis sesuai perwatakannya (Sumardjo, 1980:67).

Selain segi cerita dan gambar, ciri khas bentuk prasi adalah tersusun dari cakepan (cover) yang terbuat dari pohon bambu tua dan diawetkan di dapur tradisional Bali (paon), daun lontar yang sudah diawetkan kemudian dipres serta diikat dengan benang untuk merangkai.

\section{Fungsi Prasi dalam Masyarakat Bali}

Tarigan (1986:8) mengatakan, karya sastra yang bersifat imajinatif, dapat digunakan untuk menerangkan, menjelaskan, memahami, membuka pandangan baru dan memberikan makna kehidupan. Dengan demikian, prasi dapat dipakai sebagai penghubung bagi masyarakat sekarang dengan kehidupan masyarakat terdahulu sesuai dengan yang digambarkan pada prasi tersebut guna mengetahui dan memetik norma-norma yang luhur dari cerita prasi itu.

Selain itu, prasi dapat digunakan sebagai media pembelajaran dalam usaha untuk mempermudah guru dan siswa pada proses belajar-mengajar pembelajaran Bahasa Bali misalnya. Guru dapat menggunakan prasi sebagai media pembelajaran khususnya pada mata ajar bidang membaca dan menulis aksara Bali. Penggunaan prasi sebagai media pembelajaran bahasa Bali ini diharapkan dapat meningkatkan kemampuan siswa untuk memahami kesusastraan Bali pada umumnya dan aksara Bali dalam pembelajaran keterampilan membaca dan menulis.

Prasi juga dapat dipakai sebagai hiasan dinding untuk mempercantik ruangan. Bentuk prasi yang relatif kecil membuatnya cocok untuk dipajang di ruang tamu sebagai hiasan dinding.

\section{Tantangan Prasi (Komik Tradisional Bali) di Era Digital}

Semakin majunya zaman yang dibarengi oleh kemajuan teknologi digital semakin menjauhkan peluang tumbuhnya minat generasi muda terhadap media tradisional seperti prasi. Ada beberapa faktor yang 
menjadi tantangan serius bagi pengembangan prasi di kalangan generasi muda saat ini. Pertama, pembuatan prasi tergolong rumit jika dibandingkan dengan karya seni lainnya yang dihasilkan menggunakan teknologi modern yang jauh lebih praktis dan efisien. Pembuatan prasi dari mulai menyiapkan bahan-bahan hingga proses penulisannya memiliki tingkat kerumitan yang sukar diterima oleh generasi masa kini yang terbiasa bekerja secara instant.

Kedua, tampilan prasi secara visual kurang menarik bagi kalangan generasi muda. Ilustrasi dan teks prasi yang berkarakter tradisional dengan kisah-kisah pewayangan cukup sulit dimengerti oleh sebagian besar generasi muda yang jarang berinteraksi dengan budaya tradisional. Mereka lebih mengenal tokohtokoh dan kisah-kisah animasi di film Holywood dan game online yang berpola digital dibandingkan sosok pewayangan.

Ketiga, selain teks dan ilustrasinya yang kurang menarik, materialnya yang terbuat dari daun lontar dan bilah bambu dengan pewarna hitam dari arang kemiri, memberi kesan kuno dan primitif. Sementara teknik menulis prasi yang menoreh dengan pisau pengrupak juga sangat sulit dilakukan oleh generasi muda masa kini yang telah dimanjakan oleh keyboard gadget dan alat tulis digital.

Keempat, prasi juga sulit ditemui di sembarang tempat, sehingga kemudahan untuk mendapatkannya menjadi kendala yang makin menjauhkan prasi dari jangkauan generasi muda. Kesan sakral akibat bentuknya yang mirip lontar-lontar kuno juga memberi rasa sungkan untuk menyentuh secara leluasa. Intinya, generasi muda sukar mengakses prasi baik dari konten maupun fisiknya karena peredarannya langka dan tidak semudah mengakses media digital.

Sebagaimana nasib kesenian dan kebudayaan tradisional lain yang tidak pandai memanfaatkan keberadaan media digital untuk menunjang eksistensinya, prasi pun juga dapat mengalami nasib serupa. Jika tidak segera mendapat penanganan yang serius dan efektif, maka prasi sebagai karya local wisdom yang jauh dari sentuhan teknologi modern, dengan proses pengerjaan yang sangat rumit menggunakan alat dan bahan tradisional yang kurang bersahabat dengan teknologi kekinian, akan membuat generasi muda Bali kurang tertarik untuk menekuninya.

\section{Peluang Prasi (Komik Tradisional Bali) di Era Digital}

Meskipun prasi merupakan karya tradisional yang hampir ditinggalkan, prasi masih ada harapan untuk berkembang. Hal ini bergantung dari efektivitas dan intensitas upaya yang dilakukan oleh pemerintah untuk memberikan pembinaan terhadap generasi muda.

Lomba nyurat prasi merupakan salah satu wujud dari usaha pemerintah tersebut. Semakin sering diadakan lomba ini, maka akan semakin besar peluang mengembangkannya. Tujuan lomba semata-mata supaya generasi muda Bali tertarik untuk belajar dan mengembangkan tradisi menulis prasi. Agar tidak hanya didominasi kaum tua, maka pada setiap kegiatan lomba prasi perlu pula diadakan untuk tingkat remaja untuk memotivasi remaja-remaja Bali tertarik belajar menulis prasi. Dengan demikian prasi akan lebih berpeluang untuk berkembang.

Prasi sesungguhnya sangat menjanjikan peluang bagi komunitas pembuatnya karena karya prasi ternyata sangat diminati oleh para wisatawan asing. Hal ini dapat diketahui dari larisnya penjualan prasi di Desa Tenganan Pagringsingan, Kecamatan Manggis, Kabupaten Karangasem. Prasi ini biasanya digunakan sebagai cinderamata untuk hiasan dinding. Prasi dapat menjadi alternatif pilihan komoditi karya seni tradisional khas Bali. Cinderamata prasi dapat ditemui di daerah pariwisata, seperti Gua Lawah (Klungkung), Tenganan, dan di tempat-tempat wisata lainnya di Bali. Biasanya pada bulan-bulan tertentu komunitas pembuat prasi kewalahan menerima order dari para pengepul yang berasal dari Desa Tenganan Pagringsingan. 


\section{PENUTUP}

Prasi adalah cerita bergambar masyarakat Bali yang ditulis pada daun lontar. Sebagai sebuah karya sastra bentuk prasi tidak jauh berbeda dengan karya sastra lainnya. Cerita yang ditulis pada prasi biasanya diambil dari cerita Ramayana dan Mahabaratha. Namun tidak tertutup kemungkinan diambil dari cerita tantri dan yang lain sesuai pesanan. Fungsi prasi sebagai penghubung, media pembelajaran, dan hiasan dinding.

Di era digital prasi banyak memiliki tantangan, diantaranya semakin ditinggalkan oleh generasi muda karena 1) faktor pembuatan prasi tergolong rumit jika dibandingkan dengan karya seni lainnya yang dihasilkan menggunakan teknologi modern yang jauh lebih praktis dan efisien, 2) tampilan prasi secara visual kurang menarik bagi kalangan generasi muda 3) materialnya yang terbuat dari daun lontar dan bilah bambu dengan pewarna hitam dari arang kemiri, memberi kesan kuno dan primitif. 4) prasi juga sulit ditemui di sembarang tempat, sehingga sukar mengaksesnya baik dari konten maupun fisiknya dan tidak semudah mengakses media digital.

Meskipun memiliki tantangan, prasi juga menawarkan peluang. Prasi sebagai hasil karya sastra tradisional sangat digemari oleh tamu mancanegara sebagai cinderamata. Usaha pemerintah untuk melestarikan prasi sangat besar, sehingga prasi tidak mungkin punah.

\section{DAFTAR PUSTAKA}

Antara, I Gusti Putu. 2009. Sastra Bali Purwa. Singaraja. IKIP Negeri Singaraja.

Gautama, Wayan Budha. 2007. Kesusastraan Bali: Cakepan Mlajahin Kesusastraan Bali. Gianyar: Paramita Surabaya.

Pusat Pembinaan dan Pengembangan Bahasa Depdikbud, 1975. Pedoman Umum Pembentukan Istilah. Jakarta.

Rai, Ida Bagus. 2011. Prasi Selayang Pandang. Makalah ( Seminar Akademik di Jurusan Pendidikan bahasa Bali Undiksha). Singaraja.

Sumardjo, Jakob. 1980. Seluk Beluk Cerita Pendek. Bandung: Mitra Kencana.
Tarigan, Hendri Guntur. 1986. Prinsip-prisip Dasar Sastra. Bandung. Angkasa.

Tinggen, I Nengah. 1986. Aneka Sari. Singaraja. 